\title{
Proliferating mesodermal cells in murine embryos exhibiting macrophage and lymphendothelial characteristics Kerstin Buttler ${ }^{1}$, Taichi Ezaki ${ }^{2}$ and Jörg Wilting*1,3
}

\author{
Address: ${ }^{1}$ Centre of Anatomy, Department of Anatomy and Cell Biology, University Medicine Goettingen, Goettingen, Germany, ${ }^{2}$ Department of \\ Anatomy and Developmental Biology, Tokyo Women's Medical University, Tokyo, Japan and ${ }^{3}$ University Medicine Goettingen, Centre of \\ Anatomy, Department of Anatomy and Cell Biology, Kreuzbergring 36, 37075 Goettingen, Germany \\ Email: Kerstin Buttler - buttler.kerstin@med.uni-goettingen.de; Taichi Ezaki - ezakit@research.twmu.ac.jp; \\ Jörg Wilting* - joerg.wilting@med.uni-goettingen.de \\ * Corresponding author
}

Published: 22 April 2008

BMC Developmental Biology 2008, 8:43 doi:10.1/86/I47I-2/3X-8-43

This article is available from: http://www.biomedcentral.com//47I-2I3X/8/43

(C) 2008 Buttler et al; licensee BioMed Central Ltd.

This is an Open Access article distributed under the terms of the Creative Commons Attribution License (http://creativecommons.org/licenses/by/2.0), which permits unrestricted use, distribution, and reproduction in any medium, provided the original work is properly cited.
Received: 16 January 2008

Accepted: 22 April 2008

\begin{abstract}
Background: The data on the embryonic origin of lymphatic endothelial cells (LECs) from either deep embryonic veins or mesenchymal (or circulating) lymphangioblasts presently available remain inconsistent. In various vertebrates, markers for LECs are first expressed in specific segments of embryonic veins arguing for a venous origin of lymph vessels. Very recently, studies on the mouse have strongly supported this view. However, in the chick, we have observed a dual origin of LECs from veins and from mesodermal lymphangioblasts. Additionally, in murine embryos we have detected mesenchymal cells that co-express LEC markers and the pan-leukocyte marker CD45. Here, we have characterized the mesoderm of murine embryos with LEC markers ProxI, Lyve-I and LAIO2 in combination with macrophage markers CDIIb and F4/80.
\end{abstract}

Results: We observed cells co-expressing both types of markers (e.g. ProxI - Lyve-I - F4/80 triple-positive) located in the mesoderm, immediately adjacent to, and within lymph vessels. Our proliferation studies with $\mathrm{Ki}-67$ antibodies showed high proliferative capacities of both the Lyve-Ipositive LECs of lymph sacs/lymphatic sprouts and the Lyve-I-positive mesenchymal cells.

Conclusion: Our data argue for a dual origin of LECs in the mouse, although the primary source of embryonic LECs may reside in specific embryonic veins and mesenchymal lymphangioblasts integrated secondarily into lymph vessels. The impact of a dual source of LECs for ontogenetic, phylogenetic and pathological lymphangiogenesis is discussed.

\section{Background}

The important physiological and pathophysiological roles of the lymphatic vascular system for fluid homeostasis, immune surveillance, inflammation and tumour metastasis justify intensive studies of this hardly visible portion of the vascular system $[1,2]$. Insufficient development of lymph vessels becomes immediately apparent as lymph oedema, which mostly affects the legs and the genital region of patients. Primary lymph oedema (Nonne-Milroy Syndrome) is caused by mutations in the tyrosine kinase domain of the Vascular Endothelial Growth Factor Receptor-3 (VEGFR-3) gene on 5q35.3 [3,4]. Kaposi's sarcoma probably represents a form of lymphatic endothelial cell (LEC) hyperplasia [5], but circulating precursor cells may also be involved [6]. However, it is still not clear whether lymphangioma, which is found in $1.2-2.8 \%$ of 
infants [7], is due to hyperplasia of LECs or structural malformations of lymph vessels [8]. These uncertainties with respect to the pathobiology of lymph vessels are based on the fact that the mechanisms of normal embryonic lymphangiogenesis and the origin of LECs are not sufficiently well understood.

Following the identification of specific markers for LECs, our knowledge of the structure and function of lymph vessels and the molecular equipment of LECs has increased enormously in recent years $[9,10]$. Nevertheless, the embryonic origin of the lymphatic vascular system has been discussed controversially for more than a hundred years, and is still open for discussion. The two main theories are the 'centrifugal' and 'centripetal' theory. The first was set up by Sabin $[11,12]$ and Lewis [13] and proposes a venous origin of the lymph sacs (which are the first clear morphological signs of lymph vessel development), with subsequent sprouting of lymph vessels into all tissues and organs of the body. The second was set up by Huntington and McClure [14] and proposes formation of lymphatic vessels from mesenchymal 'lymphatic clefts', which, nowadays, are called lymphangioblasts. Several recent studies clearly show development of LECs from the venous system in the murine embryo [15-17]. However, an intermediate position favouring a dual origin from embryonic veins and mesenchymal lymphangioblasts was defined by studies on avian embryos and Xenopus tadpoles [18-20]. Migration of mesenchymal lymphangioblasts, which are originally located in the venous system and delaminate from the endothelium, has been observed in fish [21]. Additionally, our previous studies have demonstrated the existence of mesenchymal cells which co-express leukocyte (CD45) and lymphendothelial markers (Prox1, Lyve1) in mouse embryos [19]. Recent studies on pathological lymphangiogenesis in adult mice have provided evidence of a role of circulating endothelial progenitor cells (CEPCs) and macrophages (CD11b and F4/80 positive) in this process [22-24]. Evidence of CEPCs in humans has been provided in studies on post-transplantation Kaposi's sarcoma [6] and kidney graft rejection [25].

The detection of cells, which co-express macrophage and lymphendothelial markers in the adult mouse, prompted us to investigate such cells in the murine embryo. We used antibodies against CD31/PECAM-1, a pan-endothelial marker, in combination with LEC-specific markers: Prox1, a homeobox transcription factor, Lyve-1, a hyaluronan receptor, and LA102, a recently defined new epitope on LECs [26]. Double and triple staining were then performed with macrophage markers CD11b and F4/80. These studies, in combination with the proliferation marker Ki-67, provide evidence for the existence of actively dividing mesenchymal cells, which co-express macrophage and lymphendothelial markers in early mouse embryos. The mesenchymal localization of the cells in murine embryos suggests an additional source of LECs, which may integrate into lymph vessels that have primarily originated and sprouted from embryonic veins. The existence of highly mobile (macrophage-like) cells with LEC characteristics seems to be relevant for pathological lymphangiogenesis and inflammation-associated organ rejection [reviews see: $[27,28]]$.

\section{Results \\ Cells with pan-endothelial, lymphendothelial and macrophage characteristics}

During early stages of lymphendothelial commitment, the LEC markers Prox1 and Lyve-1 are expressed by cells of the cardinal veins of the mouse on approximately embryonic day (ED) 9.5 [17]. These cells are also positive for CD31/PECAM-1, a pan-endothelial marker, which is strongly expressed in blood endothelial cells (BECs) and more weakly in LECs $[29,30]$. The precursor cells give rise to lymph sacs which, in the jugular region, are located in the angle between anterior and posterior cardinal veins [15], as can be demonstrated by staining with anti-Lyve-1 antibodies (Fig. 1). However, the lymph sacs are not the only structures which are Lyve-1-positive. There are large numbers of scattered cells, preferentially located in the loose mesenchyme (Fig. 1A). On ED 13.5 the lymphatic vascular system of murine embryos is made up of a deep and a superficial part. The deep part consists of the lymph sacs located alongside the jugular segment of the cardinal veins (Fig. 1A,B). The superficial lymphatics are located in the dermis. They are connected to the deep system by lymphatic vessels, which are located in the mesenchyme underneath the skeletal elements of the shoulder girdle. Additionally, there are large numbers of scattered Lyve-1positive cells in the loose mesenchyme of the dermis, the primitive meninges and the parapharyngeal region. The neural tube, skeletal elements and muscles do not contain such cells.

Our double staining protocol confirms that LECs of the jugular lymph sacs are Prox $1^{+}$and Lyve-1+ (Fig. 1C). The new lymphendothelial marker LA102, a monoclonal antibody recognizing a $25-27 \mathrm{kDa}$ protein, specifically reacts with lymphatic vessels of the adult mouse, except for those of the thoracic duct and the marginal sinus of lymph nodes, but not with any blood vessels [26]. We investigated the expression of LA102 during early embryonic lymphangiogenesis of ED 11.5 - 13.5 mice and performed double staining with either Prox1 or Lyve-1. On ED 12.5 and ED 13.5, we observed that LECs in the jugular lymph sacs were double positive for Prox1 and LA102 (Fig. 1D) as well as Lyve-1 and LA102 (Fig. 1E). The same results hold true for the superficial lymphatics of the dermis (Fig. 1F). However, in the mediastinal region, we found some lymphatic vessels which expressed only Lyve- 

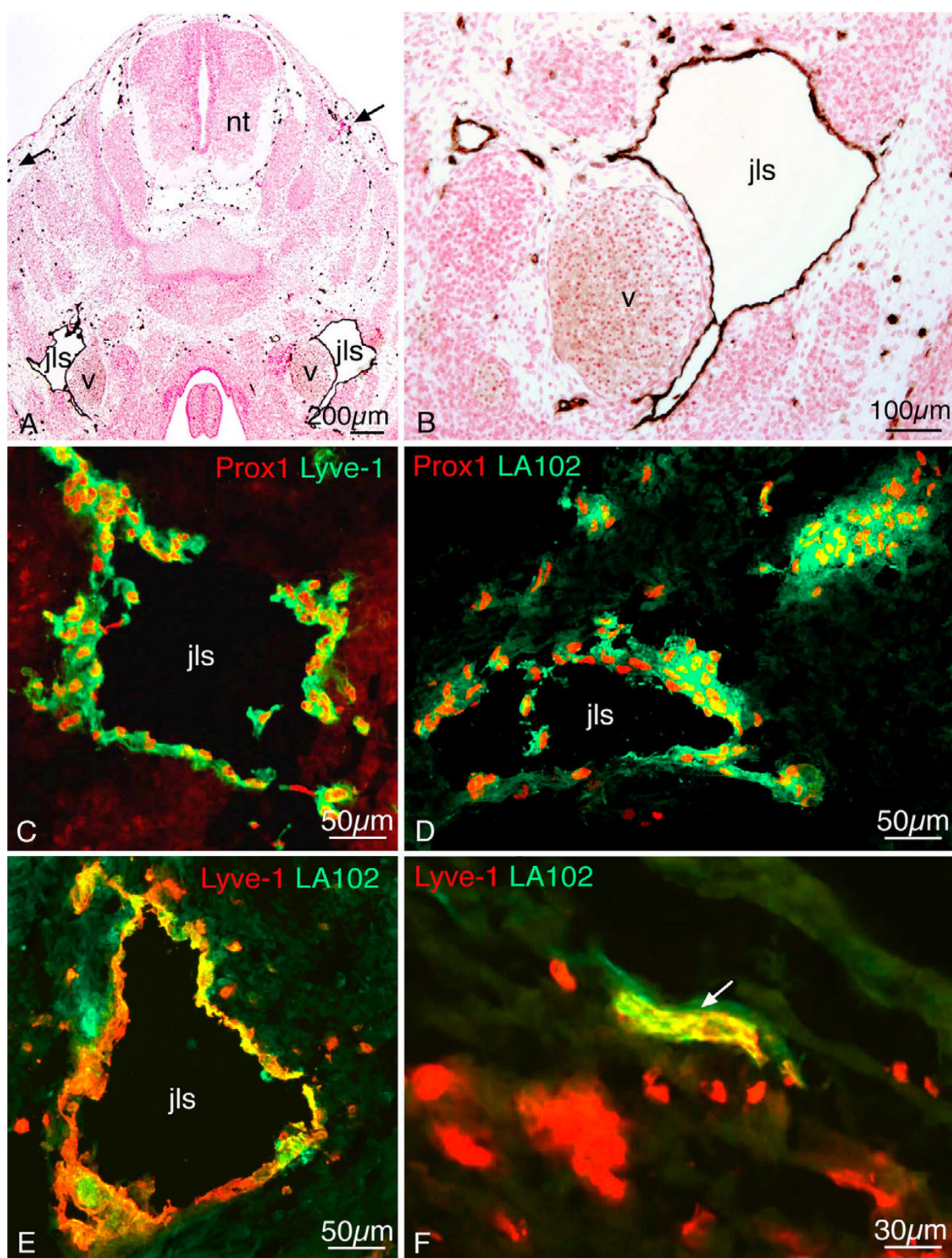

Figure I

Jugular lymph sacs of murine embryos. Lyve-I staining of paraffin sections (A, B) and double staining of cryo-sections (CF) of ED I3.5 (A-C, E, F) and I2.5 (D) mice. A, B) The jugular lymph sacs (jls) are Lyve- I+ and located dorso-laterally of the cardinal vein (v). Many scattered Lyve- $\mathrm{I}^{+}$cells are located superficially in the developing dermis (arrows). nt, neural tube. B) Higher magnification of A showing JLS in close proximity to the cardinal vein. C) Lymph sacs express ProxI (red) and Lyve-I (green). D) ProxI (red) and LAI02 (green). E) Lyve-I (red) and LAI02 (green). Note double positive LECs, although staining of lymph sac LECs with LAIO2 is heterogeneous. F) Lymphatic vessel (arrow) in the dermis is double positive for Lyve-I and LAIO2 (yellow). 
1, while others demonstrated Lyve-1 and LA102 coexpression (data not shown).

The data show that all three markers, Prox1, Lyve-1 and LA102 are expressed by LECs of lymph sacs and lymph vessels, although each is also expressed by some nonendothelial cell types. In order to characterize the scattered mesenchymal Lyve-1+ cells shown in Figure 1A, we used double and triple staining with lymph/endothelial and macrophage markers. In our previous studies, we showed that some mesenchymal Lyve-1+ cells coexpressed Prox1 [19]. Here, we detected a small number of Prox $1^{+} / \mathrm{CD} 31^{+}$mesenchymal cells in the dermatomes on ED 10 (Fig. 2A,B). CD31 expression in these cells, which we regard as lymphangioblasts, is lower than in BECs. Co-staining with LA102 and Prox1 antibodies revealed that some scattered cells in the mesenchyme are double positive (Fig. 2C). On ED 12.5 we observed single cells in the mesenchyme surrounding the neural tube which co-expressed Lyve- 1 and LA102, but there were also cells only positive for LA102 (Fig. 2D). It has been reported that $\mathrm{CD} 11 \mathrm{~b}^{+}$macrophages may contribute to pathological lymphangiogenesis in the cornea of adult mice [22]. We detected a small number of Prox $1^{+} / \mathrm{CD} 11 \mathrm{~b}^{+}$ cells in the mesenchyme of ED 12.5 mice (Fig. 2E). LECs of the jugular lymph sacs on ED 13.5 were CD11b-negative, but a few Lyve- $1^{+} / \mathrm{CD} 11 \mathrm{~b}^{+}$cells were located immediately adjacent to the lymph sacs (Fig. 2F), and appeared to be integrated into the superficial dermal lymph vessels (Fig. 2G).

We then used the macrophage marker F4/80 for further characterisation of mesenchymal Lyve- $1^{+}$cells. A large number of scattered cells of the dermatomes, mediastinum and pimitive meninges co-expressed Lyve- 1 and F4/ 80 in ED 13.5 embryos and some cells expressed only Lyve-1 or F4/80 (Fig. 3). There was a distinct difference between the frequencies of $\mathrm{CD} 11 \mathrm{~b}^{+}$and $\mathrm{F} 4 / 80^{+}$cells in the mesenchyme. Many more F4/80+ cells could be found, and many of these were Lyve- $1^{+}$. We, therefore, extended our studies by applying three markers: Prox1, Lyve-1 and $\mathrm{F} 4 / 80$. We found cells in the developing lymph sacs positive for all three markers in ED 13.5 mice (Fig. 4A-F). More peripherally, in developing lymph vessels, we also found a small number of cells positive for all three markers (Fig. 5A,B). In very rare cases, we could observe various marker combinations in adjacent cells of lymph vessels. Figure 5A shows such an example with 3 cells: one positive only for F4/80, one expressing F4/80 and Lyve-1, and a third positive for F4/80, Lyve- 1 and Prox1. The fact that two LEC markers, Prox1 and Lyve-1, can be found in F4/ $80^{+}$cells, which appear to be integrated into lymph vessels, is a strong indication for a mesenchymal source of LECs in murine embryos.

\section{Proliferation studies}

Ki-67 is a well-established proliferation marker and is increasingly expressed in the nucleus in all active phases of the cell cycle, but not in $\mathrm{G}_{0}$ phase [31]. To extend our studies on the source of LECs, we performed double staining with anti-Ki-67 and anti-Lyve-1 antibodies of ED 11.5 - 13.5 mice. Nuclei were counter stained with 4',6-diamidino-2-phenylindol (DAPI). Double positive LECs could be detected in regions of active lymphangiogenesis: the early jugular veins, the jugular lymph sacs, which extended sprouts into dorso-lateral directions, the mediastinum and the dermis (Fig. 6). Mouse embryos on ED 11.5 exhibited very few cells in the cardinal veins positive for both markers, whereas LECs of the developing jugular lymph sacs as well as mesenchymal cells in the dermis coexpressed Ki-67 and Lyve-1 at high rates (Fig. 6A,B). The dermatomes of ED 12.5 and 13.5 mice displayed scattered Lyve- $1^{+}$cells, which also showed proliferating characteristics (55\% and 33\%, respectively; Fig. 7). However, the total number of Lyve-1+ $1^{+}$cells in the dermatomes was low compared with the number of lymph sac ECs. In the jugular lymph sacs (Fig. 6C) and in sprouts derived from them (Fig. 6D) the Ki-67 labelling rate was $22-30 \%$ (Fig. $7)$. The data show that a greater number of Lyve-1+ cells are present in the lymph sacs than in the dermatomes, but the latter proliferate at equal or, in ED 12.5 embryos, even higher rates.

\section{Discussion}

\section{Embryonic lymphangiogenesis}

Our data show that there is a cell type in early mouse development, which combines lymphendothelial (Lyve$1^{+}$, Prox $\left.1^{+}\right)$and macrophage $\left(\mathrm{F} 4 / 80^{+}\right)$characteristics. Also, there are cells that express Lyve- 1 and F4/80, as well as cells that have only one of these markers. The triplepositive cells appear to be integrated into the lining of early lymph vessels, and, in sum, the data are in favour of an origin of LECs from mesenchymal, macrophage-like cells. Although these cells may contribute only to the minor part of the lymphovascular system, their existence and possible contribution to pathological lymphangiogenesis should not be neglected.

Recent data by Srinivasan et al. [15] have provided clear evidence that the major part of the lymphovascular system of mice is of venous origin. The jugular segment of the cardinal veins is the source of the jugular lymph sacs, which then grow into peripheral parts of the body. Prox1expressing venous ECs are the source of the jugular lymph sacs in the anterior region of the embryo. The posterior cardinal veins give rise to the posterior lymph sacs, which are the source of the lymphatics in the mesenteries and the posterior organs. The earliest Prox1-positive ECs are located in the jugular segment of the cardinal veins of ED 9.75 mice. A third place of origin of lymphatics is the 

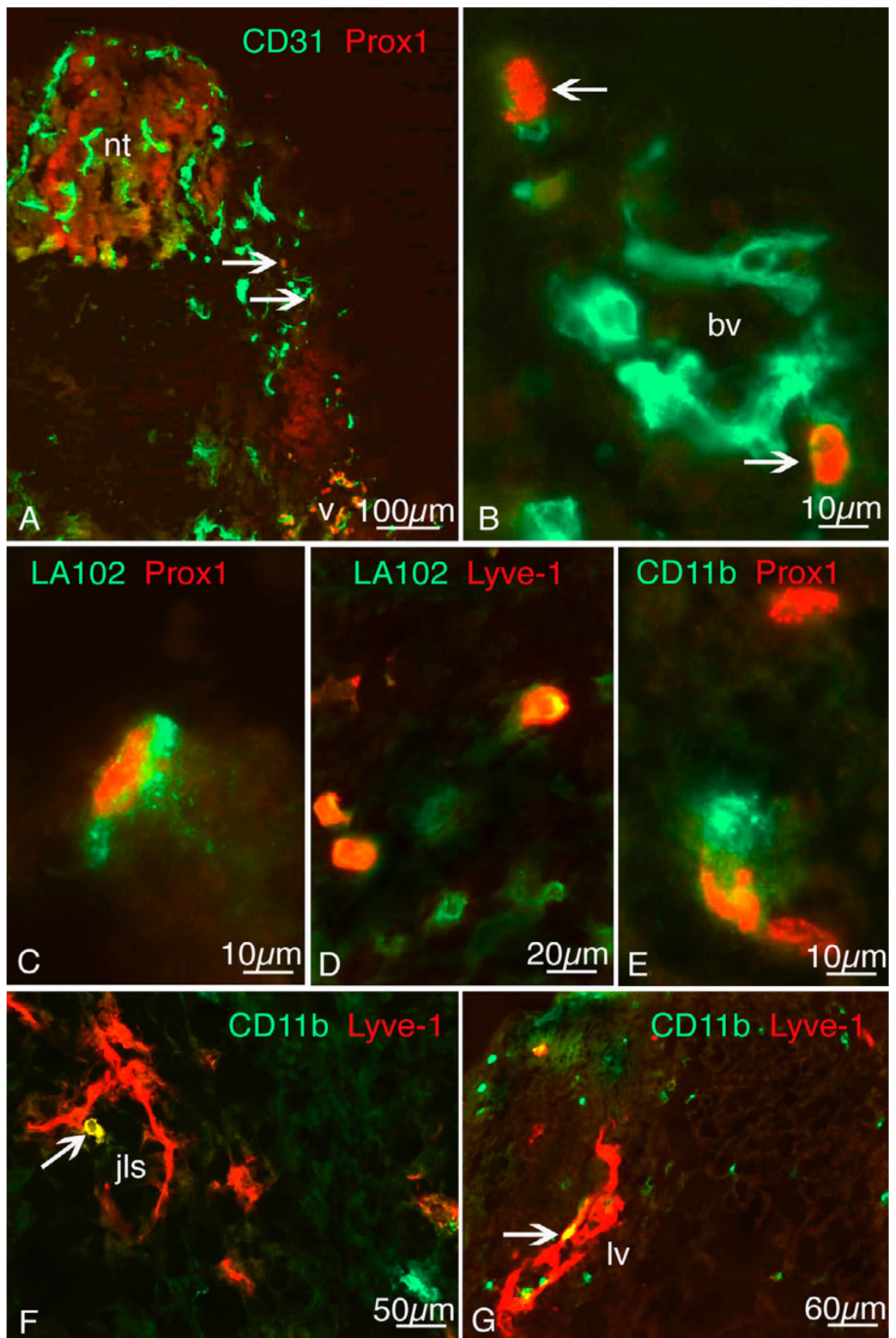

\section{Figure 2}

Double staining of scattered mesodermal cells with pan-endothelial, lymphendothelial and macrophage markers of ED I0 (A, B), ED I 2.5 (D, E) and ED I3.5 (C, F, G) mouse embryos. A) Two mesenchymal cells of the dermatome (arrows) which are located at a great distance from the cardinal vein (v) express CD3I (green) and Proxl (red). nt, neural tube. B) Higher magnification of A). Note weak CD3I expression of Prox I+ mesenchymal cells (arrows) as compared to blood vessels (bv). C) Cells double positive for lymphendothelial markers LAI02 (green) and ProxI (red), and D) LAI02 (green) and Lyve-I (red). E) Cells double positive for macrophage marker CDI Ib (green) and lymphendothelial marker ProxI (red). F) Some cells co-express (yellow) CDI Ib (green) and Lyve-I (red) in the mesenchyme adjacent to the JLS, and G) in the dermis, where a cell positive for both markers (arrow) seems to be integrated into a lymph vessel (Iv). 


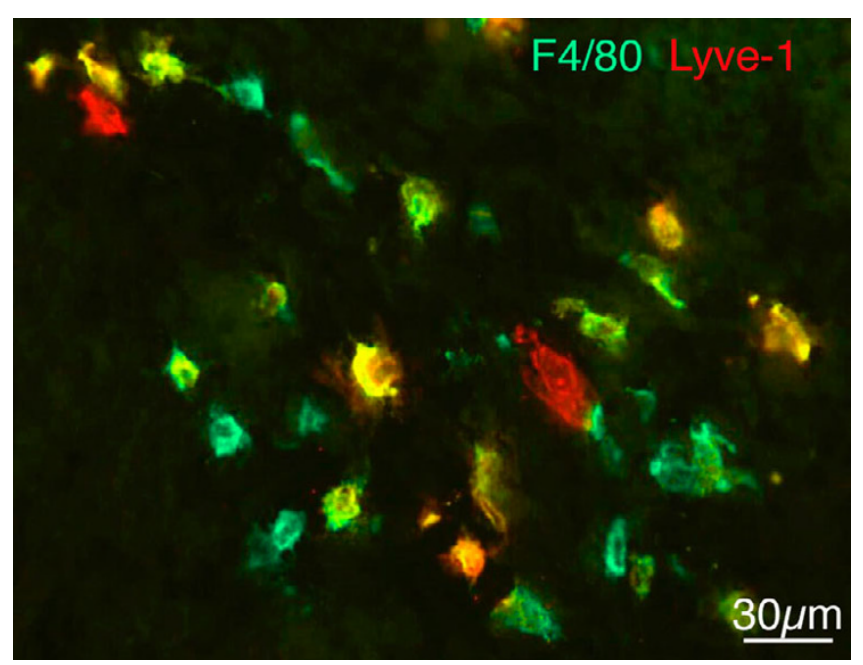

Figure 3

F4/80 (green) and Lyve-I (red) staining of ED I3.5

mice. Many of the cells in the dermis are double positive (yellow), but some only express F4/80 or Lyve-I.

orbital region [15]. Loss of Prox1 expression abolishes development of lymphatics [17]. Regular development of veins is another prerequisite for the generation of LECs. The absence of Coup-TFII, an orphan nuclear receptor transcription factor, causes embryonic death around ED 10 , abnormal expression of arterial marker genes in the veins, and loss of jugular lymph sacs [15,32-36]. A contribution of hematopoietic cells to the lymphatics does not seem to exist. Runx1-null mice, which do not develop definitive hematopoietic cell [37], have normal jugular lymph sacs, and descendents of hematopoietic stem cells are not detectable in the mouse carrying a reporter gene under the control of the Runx1 promoter [15]. In all, these data show that the venous system is the main source of the embryonic lymphovascular system in mice.

Nevertheless, even the highly detailed studies on the venous origin of embryonic LECs cannot rule out the possibility of a minor contribution of mesenchymal cells to the lymphatics $[15,17]$. In both of the studies cited, scattered Prox1-positive cells were observed along the anteroposterior axis of the body wall of early embryos - at great distances from the developing lymph sacs. In the transgenic mice studied by Srinivasan et al. [15] some cells were detected, which did not fit into the anticipated pattern of the venous origin of LECs. Thus, there are some observations that argue for an additional source of LECs. The number of LECs derived from macrophage-like, mesenchymal precursors may be low, but that does not necessarily rule out functional importance. This is supported by studies on Syk and Slp-76 knockout mice. These adapter proteins mediate outside-in integrin signalling $[38,39]$.
Mouse embryos lacking Syk and Slp-76 functions develop abnormal blood-lymph-endothelial connections, and Slp-76 deficient cells confer this phenotype on chimeric embryos [40,41]. Syk and Slp-76 are expressed in hematopoietic cells, but not in ECs. The incorporation of defective cells into abnormally fused lymph vessels and the rescue of the phenotype by GFPSlp-67-expressing circulating cells indicate a hematopoietic origin of LECs [40]. Normal $S y k$ and $S l p-76$ functions may be required in early stages of development, when hemangioblasts divide into hematopoietic and endothelial lineages. Syk and Slp-76 are expressed by platelets and eosinophils, but not macrophages or dendritic cells [40].

Incorporation of macrophages into lymph vessels has been indicated by studies on pathological lymphangiogenesis [22-24]. Our studies strongly suggest that similar mechanisms are found in embryonic lymphangiogenesis. In the adult, macrophages originate from circulating monocytes, but, in the embryo, their early development in the mesoderm is independent of the hematopoietic system. They can be isolated from the epiblast before gastrulation. So, they are present before the development of hematopoietic cells in blood islands [42]. After gastrulation, macrophages are found in all embryonic compartments, which is also evident in the studies presented here. Mesenchymal macrophages can give rise to stationary cells, which is best documented in the central nervous system (CNS) where they form the microglia [43], which has self-renewal potential. Our studies provide initial evidence for the incorporation of macrophage-like cells into the lining of lymph vessels during normal development.

There are large numbers of Lyve- $1^{+}$single cells in the mesenchyme of murine embryos, which are highly proliferative and obviously represent a heterogeneous cell population. Many of the cells express the pan-leukocyte marker CD45 [19]. Here, we show that some of the cells co-express other LEC markers such as Prox1 and LA102. Co-localization of Prox 1 and CD31/PECAM-1 in scattered cells in the dermatomes of ED 10 mouse embryos is a strong indicator of a lymphangioblastic cell population. Prox1 is the most reliable marker that distinguishes between LECs and BECs in healthy and diseased tissues $[29,30]$, and CD31 is a highly reliable pan-endothelial marker. In birds, similar cells are present, and grafting of quail dermatomes into chick embryos has demonstrated the lymphangiogenic potential of this tissue [20]. Many of the Lyve- $1^{+}$single cells in the mesenchyme express F4/80, but only some are CD11b+. The F4/80 antibody recognises an extra-cellular membrane molecule, highly restricted to mature macrophage subpopulations. The antigen is not present on granulocytes, lymphocytes, mast cells, platelets, endothelial cells and blood monocytes [44]. CD11b is found on 'classical' macrophages such as 




\section{Figure 4}

Double and triple staining of ED I I.5 (A) and ED I 3.5 (B - F) mouse embryos with Prox I (red), Lyve- I (blue), and F4/80 (green). A) Cell showing co-expression of Proxl and F4/80 (arrow), whereas another cell is only F4/80 positive. B) Overview showing the jugular lymph sac (jls) and the cardinal vein (v). Proxl and Lyve-I are co-expressed in LECs of the jls. Arrow indicates integration of $\mathrm{F} 4 / 80^{+}$cell into the jls. C) Higher magnification of $\mathrm{B}$ ) showing triple positive cells of the JLS. D) Proxl, E) Lyve-I, F) F4/80. 

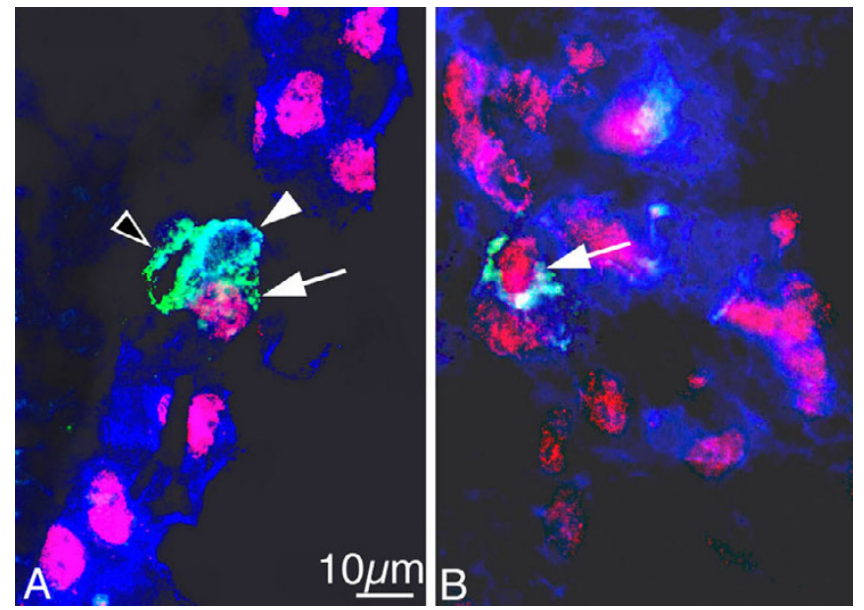

Figure 5

Triple staining of ED I 3.5 mouse embryos with Prox I (red), Lyve-I (blue), and F4/80 (green). A, B) Triple positive cell integrated in a lymphatic vessel (arrow in $A$ and B). A) Cell showing co-expression of Lyve-I and F4/80 (white arrowhead), whereas another cell is only $\mathrm{F} 4 / 80$ positive (open arrowhead).

alveolar and peritoneal macrophages, but not on dendritic cells [45]. We detected a small number of Prox1Lyve-1-F4/80 triple-positive cells, which were obviously integrated into the lining of lymph vessels. Although this is a rare event, it demonstrates heterogeneity of LECs, probably due to heterogeneity of lymphangiogenic mechanisms, which may be relevant not only during embryonic lymphangiogenesis, but also in phylogeny and during pathological lymphangiogenesis.

\section{Phylogenetic lymphangiogenesis}

Development of LECs from macrophage-like progenitors might reflect an ancestral mechanism. This assumption is based on the observation that insects, which do not possess ECs [46], have macrophages that express ancestors of typical angiogenesis-associated molecules of vertebrates [47-49]. The tubular heart (also called dorsal vessel) of insects is lined by contractile muscle cells, but not ECs [46]. In Drosophila supply with oxygen is accomplished by a tracheal system. Red blood cells are not present and the so-called hemolymphatic system fulfils functions of a typical lymphatic system. It has, therefore, been speculated that the lymphovascular system evolved before the blood vascular system, although during ontogeny the latter develops first [50]. Three types of immune cells are found in Drosophila: plasmatocytes, crystal cells and lamellocytes [51]. Plasmatocytes, which are capable of phagocytosis, are comparable to the monocyte/macrophage lineage of vertebrates. They possess a single ancestor for the VEGF (Vascular Endothelial Growth Factor) and PDGF (Platelet-derived Growth Factor) receptors found in vertebrates.
This receptor, called PVR, directs immune cell migration $[48,49,52]$. The VEGF-PDGF-system is indispensable for the development of vessels in vertebrates (ECs, pericytes, smooth muscle cells), and it is tempting to speculate that vascular wall cells are derived from macrophage-like cells during phylogeny, and some LECs still do so during ontogeny.

\section{Pathological lymphangiogenesis}

Lymphangiogenesis in embryos and adult organisms have many mechanisms in common, but they may also differ to some extent. Lymphangiogenesis in the adult takes place in the proliferation phase of the endometrium [53]. Pathological lymphangiogenesis can be observed in inflammatory diseases such as Crohn's disease and ulcerative colitis [54], in and around tumours that express the lymphangiogenic growth factors VEGF-C and -D [55-57], and during wound healing, where it occurs after blood vessels have formed [58]. In these scenarios, new lymphatics are mostly formed from pre-existing ones, however, exceptions have been observed. One of these exceptions is the healing of dermal wounds in the mouse tail [59]. In this model, LECs do not sprout from lymph vessels, but migrate as single cells from distal to proximal parts of the tail and organize into vessels in the direction of interstitial fluid flow. It is tempting to speculate that the dermis of adult organisms still contains lymphendothelial precursor cells, which is in line with our observation of lymphangioblasts in the early dermatomes of murine and avian embryos [2,19].

Macrophages may support pathological lymphangiogenesis in two ways: either by transdifferentiation and direct incorporation into the endothelial layer or by stimulating division of pre-existing local LECs $[22,23,60]$. Thereby, VEGF-C seems to have a dual role as inducer of LEC proliferation and chemoattractant of macrophages [61]. In diabetes, wound healing is impaired, due to decreased numbers of macrophages (F4/80 $0^{+}$, Lyve- $1^{+}$, podoplanin ${ }^{+}$) and lymph vessels [62]. A pool of macrophages expressing VEGFR-3, CD45 and CD11b has been found in the conjunctiva of normal and inflamed murine eyes [63]. However, further studies are needed to clarify whether their incorporation into lymph vessels is permanent or represents some kind of lymphendothelial mimicry [24].

Evidence for circulating cells with lymphendothelial characteristics has been found in human diseases. In patients with gender-mismatched renal transplants and inflammation-associated transplant rejection, Kerjaschki et al. [25] observed lymphangiogenesis with Ki-67 labelling rates of $2.3 \%$ of LECs, and incorporation of circulating recipientderived cells into kidney lymph vessels in the range of 2.7 - 7\%. The Ki-67 labelling rates are clearly lower than those we observed in embryonic LECs (in the mouse), 

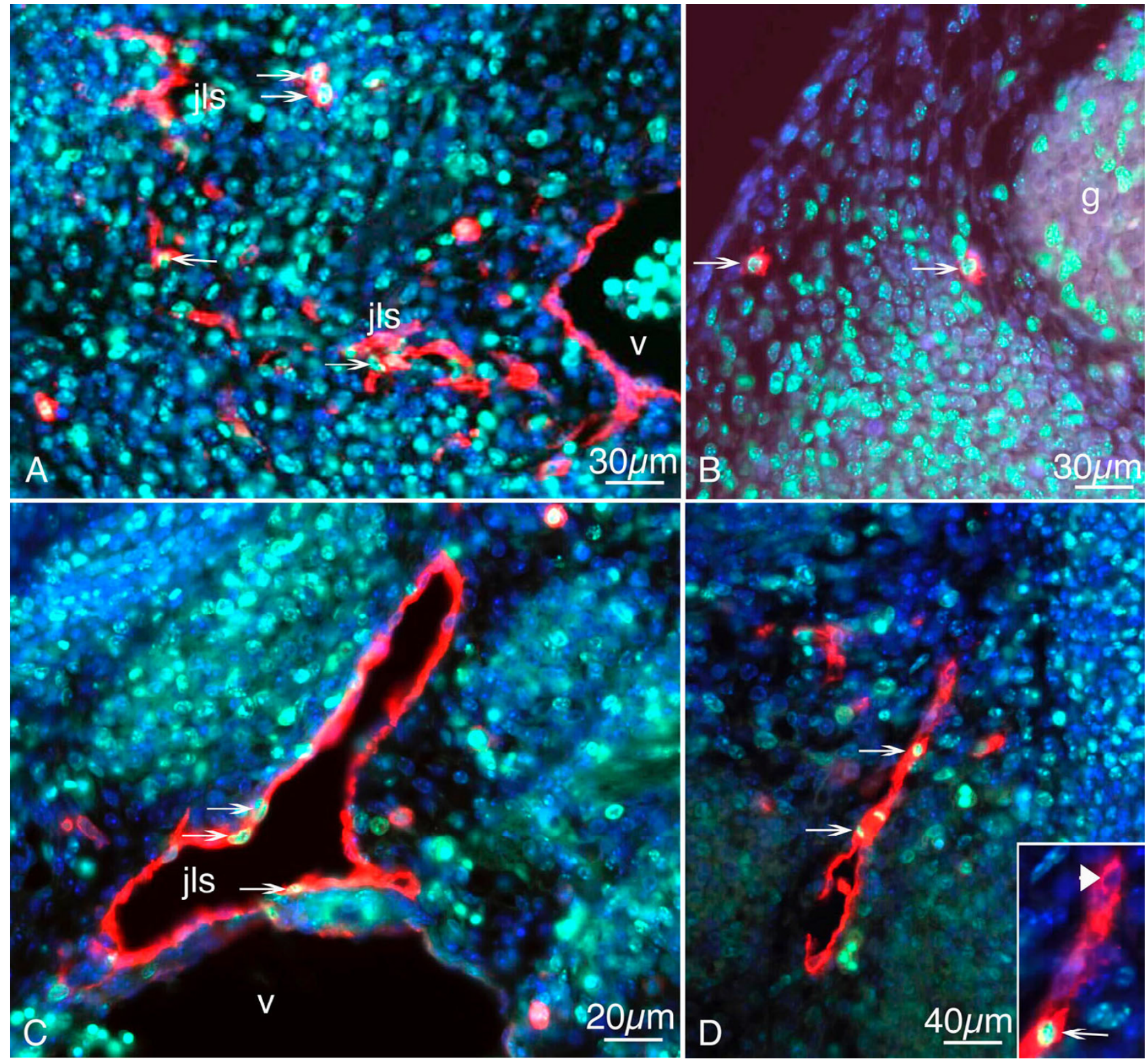

Figure 6

Paraffin sections of mouse embryos stained with antibodies against Ki-67 (green) and Lyve- I (red). Counter staining was performed with DAPI (blue). A) On ED II.5, there are proliferating LECs in the developing jugular lymph sacs (jls) (arrows), but no double positive cells in the cardinal vein (v). B) Two mesenchymal cells positive for the markers located in the dermatome (arrows). g, spinal ganglion. C) JLS of ED 12.5 mice with LECs (arrows) expressing Ki-67 and Lyve-I. D) Sprout from the JLS containing proliferating cells (arrows). Inset: Higher magnification showing Ki-67-positive (arrow) and negative (arrowhead) LECs.

whereas the incorporation of circulating progenitor cells into the lining of lymph vessels appears to be relatively high in the adult human. The second disease, which shows involvement of circulating lymphatic progenitor cells, is Kaposi's sarcoma (KS). The cell of origin in KS has long been a subject of debate. Mesenchymal cells, smooth muscle cells, BECs, LECs, Schwann cells and fibroblasts have been discussed. An endothelial origin has then been favoured, but it has remained unclear whether these are BECs or LECs $[64,65]$. Studies on the expression of lymphendothelial markers VEGFR-3, podoplanin and Lyve-1, and studies showing the mitogenic effect of VEGF-C seem 


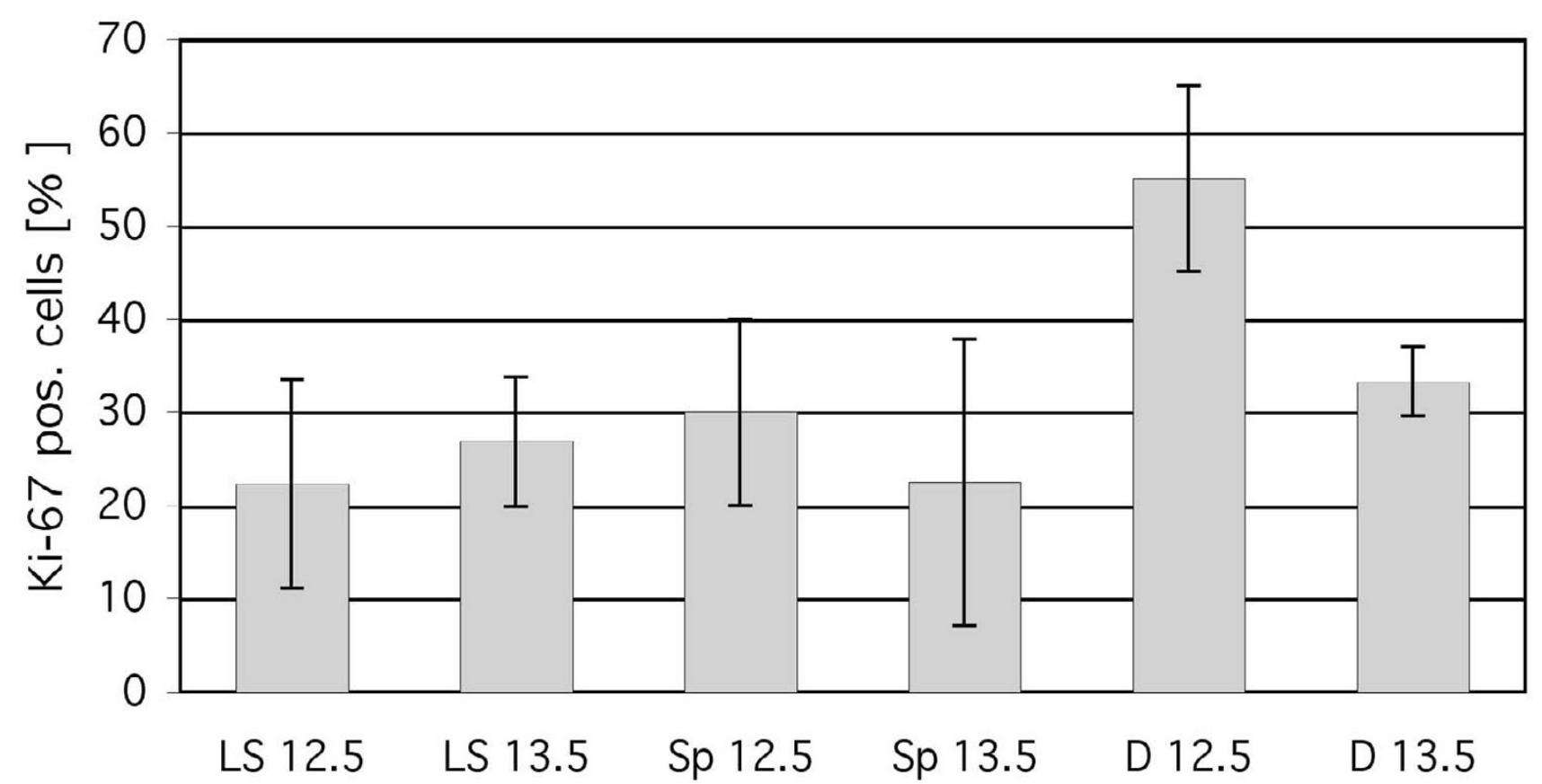

\section{Figure 7}

Proliferation studies of Lyve- I+ cells with Ki-67 antibodies in ED I 2.5 and ED I3.5 mice. For each ED, at least 5 sections of at least 3 mice were evaluated. The total number of cells counted was: 197 in lymph sacs (LS) on ED I2.5; 406 in lymph sacs (LS) on ED 13.5; 45 in sprouts from lymph sacs (Sp) on ED I2.5; 75 in sprouts from lymph sacs (Sp) on ED I3.5; 43 in scattered cells in the dermatomes (D) on ED 12.5 and 40 in scattered cells in the dermatomes (D) on EDI3.5. Mean and standard deviation are shown. The value for D 12.5 is significantly higher than all others.

to prove that KS is derived from LECs [5]. However, examination of biopsies from KS skin lesions, which developed after transplantation in immuno-suppressed recipients of kidneys, showed that a high proportion of KS cells were of donor (kidney) origin [6]. These findings suggest that KS cells are derived from highly mobile cells. It is probable that these are macrophage-like, which originated in the donor organ. Cells with macrophage and endothelial characteristics have been isolated from peripheral blood of KS patients [66].

\section{Conclusion}

In summary, we describe mesenchymal cells with macrophage and lymphendothelial characteristics in murine embryos. These cells seem to participate in normal lymphangiogenesis and might represent a relict of the phylogenetic development of lymph vessels from immune cells. Similar cells may take part in pathological lymphangiogenesis in the mouse and in human beings, and may be the cell of origin in Kaposi's sarcoma.

\section{Methods}

Animals

NMRI and C57BL/6 wild type mouse embryos from ED 10 to 13.5 were studied. Embryos were removed from the uterus and remained either unfixed, or were fixed in $4 \%$ paraformaldehyde (PFA), or in 100\% ethanol containing $3 \%$ acetic acid. We did not observe any differences between the two strains.

\section{Immunohistochemistry}

Mouse embryos were embedded in paraffin and sectioned into $8 \mu \mathrm{m}$ slices with a microtome (Leica, Bensheim, Germany) and placed onto slides. Sections were stained with rabbit-anti-mouse Lyve-1 antibodies (Regeneron, Tarrytown, NY). The secondary antibody was peroxidase-conjugated goat-anti-rabbit IgG (Sigma-Aldrich, Taufkirchen, Germany). Diaminobenzidine was used as chromogen. Sections were counter stained with nuclear fast red.

\section{Proliferation studies}

Paraffin sections were stained with rabbit-anti-mouse Lyve-1 antibodies [67,68] and Ki-67 (Dako, Hamburg, Germany). The Ki-67-antigen was used with citrate buffer in the microwave oven for antigen retrieval. The second- 
ary antibodies, Alexa 488-conjugated goat-anti-rat IgG, and Alexa 594-conjugated goat-anti-rabbit IgG (Molecular Probes, Eugene, US), were applied at a dilution of 1:200, for 1 hour $(\mathrm{h})$. Sections were counter-stained with DAPI.

\section{Immunofluorescence}

Embryos of various developmental stages remained unfixed or were fixed in 4\% PFA for 20 minutes. They were rinsed in phosphate-buffered saline (PBS), transferred to $5 \%$ and $15 \%$ sucrose in PBS, and embedded in Tissue Freeze Medium (Sakura Finetek Europe, NL). Cryosections of $20 \mu \mathrm{m}$ thickness were prepared. Non-specific binding of antibodies was blocked by incubation with $1 \%$ bovine serum albumin (BSA) for $1 \mathrm{~h}$ before incubation with the primary antisera. The following primary antibodies were used in this study for double and triple staining: rabbit-anti-mouse LYVE-1 (Regeneron, Tarrytown, NY), rat-anti-mouse CD31/PECAM-1 (1:50; BD Pharmingen, San Diego, US), rabbit-anti-human Prox1 (1:750; ReliaTech, Braunschweig, Germany), rat-anti-mouse Ki-67 (1:50; Dako, Hamburg, Germany), rat-anti-mouse CD11b (1:50; BD Pharmingen, San Diego, US), rat-anti-mouse F4/80 (1:100; Hycult Biotechnology, Uden, Netherlands), and rat-anti-mouse LA102 (pure supernatant, T. Ezaki, Japan). The sections were incubated with the primary antibodies for $1 \mathrm{~h}$, except for Prox 1 , which was incubated overnight. In the negative controls, the primary antibody was omitted. Typical controls have been published [19]. After having been rinsed, the secondary Alexa 488-conjugated goat-anti-rat IgG and Alexa 594-conjugated goatanti-rabbit IgG (Molecular Probes, Eugene, US) were applied at a dilution of 1:200. Alexa 350-conjugated goatanti-rabbit IgG (Molecular Probes) was applied at 1:50 for $1 \mathrm{~h}$. After having been rinsed, the sections were mounted under cover slips with Fluoromount-G (Southern Biotechnology Associates, Birmingham, GB). They were then viewed with the DM5000B epifluorescence microscope (Leica, Bensheim, Germany) and Zeiss Axioplan 2 LSM 510 (Zeiss, Göttingen, Germany).

\section{Authors' contributions}

$\mathrm{KB}$ carried out immunostaining and was involved in the analysis of data and preparation of the manuscript. TE performed immunostaining with lymphendothelial marker LA102. JW conceived the study and participated in its design, data analysis and manuscript preparation.

\section{Acknowledgements}

We thank Mrs. C. Maelicke for copy-editing the manuscript. This study was supported by a grant (Wi 1452/II-I) from the Deutsche Forschungsgemeinschaft.

\section{References}

I. Witte MH, Bernas MJ, Martin CP, Witte CL: Lymphangiogenesis and lymphangiodysplasia: from molecular to clinical lymphology. Microsc Res Tech 200I, 55: I22-I45.

2. Wilting J, Hawighorst T, Hecht M, Christ B, Papoutsi M: Development of lymphatic vessels: tumour lymphangiogenesis and lymphatic invasion. Curr Med Chem 2005, I 2:3043-3053.

3. Karkkainen MJ, Ferrell RE, Lawrence EC, Kimak MA, Levinson KL, McTigue MA, Alitalo K, Finegold DN: Missense mutations interfere with VEGFR-3 signalling in primary lymphoedema. Nat Genet 2000/06/03 edition. 2000, 25:153-159.

4. Irrthum A, Karkkainen MJ, Devriendt K, Alitalo K, Vikkula M: Congenital hereditary lymphedema caused by a mutation that inactivates VEGFR3 tyrosine kinase. Am J Hum Genet 2000/06/ 17 edition. 2000, 67:295-30I.

5. Cheung L, Rockson SG: The lymphatic biology of Kaposi's sarcoma. Lymphat Res Biol 2005, 3:25-35.

6. Barozzi P, Luppi M, Facchetti F, Mecucci C, Alu M, Sarid R, Rasini V, Ravazzini L, Rossi E, Festa S, Crescenzi B, Wolf DG, Schulz TF, Torelli G: Post-transplant Kaposi sarcoma originates from the seeding of donor-derived progenitors. Nat Med 2003, 9:554-561.

7. Filston HC: Hemangiomas, cystic hygromas, and teratomas of the head and neck. Semin Pediatr Surg 1994, 3:147-159.

8. Nobuhara Y, Onoda N, Fukai K, Hosomi N, Ishii M, Wakasa K, Nishihara T, Ishikawa T, Hirakawa K: TIE2 gain-of-function mutation in a patient with pancreatic lymphangioma associated with blue rubber-bleb nevus syndrome: report of a case. Surg Today 2006/02/24 edition. 2006, 36:283-286

9. Jeltsch M, Tammela T, Alitalo K, Wilting J: Genesis and pathogenesis of lymphatic vessels. Cell Tissue Res 2003, 3 | 4:69-84.

10. Alitalo K, Tammela T, Petrova TV: Lymphangiogenesis in development and human disease. Nature 2005, 438:946-953.

II. Sabin FR: On the origin of the lymphatic system from the veins and the development of the lymph hearts and thoracic duct in the pig. Amer J Anat 1902, I:367-389.

12. Sabin FR: The lymphatic system in human embryos, with a consideration of the morphology of the system as a whole. Amer J Anat 1909, 9:43-91.

13. Lewis F: The development of the lymphatic system in Rabbits. Amer J Anat 1905, 5:95- III.

14. Huntington GS, Mc Clure CFW: The anatomy and development of the jugular lymph sacs in the domestic cat (Felis domestica). Am J Anat 1910, 10:177-311.

15. Srinivasan RS, Dillard ME, Lagutin OV, Lin FJ, Tsai S, Tsai MJ, Samokhvalov IM, Oliver G: Lineage tracing demonstrates the venous origin of the mammalian lymphatic vasculature. Genes Dev 2007/I0/03 edition. 2007, $21: 2422-2432$.

16. Wigle JT, Harvey N, Detmar M, Lagutina I, Grosveld G, Gunn MD, Jackson DG, Oliver G: An essential role for Proxl in the induction of the lymphatic endothelial cell phenotype. Embo J 2002, 21:1505-1513.

17. Wigle JT, Oliver G: Prox I function is required for the development of the murine lymphatic system. Cell 1999, 98:769-778.

18. Ny A, Autiero M, Carmeliet P: Zebrafish and Xenopus tadpoles: small animal models to study angiogenesis and lymphangiogenesis. Exp Cell Res 2005/I I/29 edition. 2006, 3 I 2:684-693.

19. Buttler K, Kreysing A, von Kaisenberg CS, Schweigerer L, Gale N, Papoutsi M, Wilting J: Mesenchymal cells with leukocyte and lymphendothelial characteristics in murine embryos. Dev Dyn 2006, 235: I554-1562.

20. Wilting J, Aref Y, Huang R, Tomarev SI, Schweigerer L, Christ B, Valasek P, Papoutsi M: Dual origin of avian lymphatics. Dev Biol 2006, 292:165-173.

21. Yaniv K, Isogai S, Castranova D, Dye L, Hitomi J, Weinstein BM: Live imaging of lymphatic development in the zebrafish. Nat Med 2006, | 2:7||-7|6.

22. Maruyama K, li M, Cursiefen C, Jackson DG, Keino H, Tomita M, Van Rooijen N, Takenaka H, D'Amore PA, Stein-Streilein J, Losordo DW, Streilein JW: Inflammation-induced lymphangiogenesis in the cornea arises from CDI I b-positive macrophages. J Clin Invest 2005, I I 5:2363-2372.

23. Religa P, Cao R, Bjorndahl M, Zhou Z, Zhu Z, Cao Y: Presence of bone marrow-derived circulating progenitor endothelial cells in the newly formed lymphatic vessels. Blood 2005, 106:4184-4190. 
24. Schledzewski K, Falkowski M, Moldenhauer G, Metharom P, Kzhyshkowska J, Ganss R, Demory A, Falkowska-Hansen B, Kurzen H, Ugurel S, Geginat G, Arnold B, Goerdt S: Lymphatic endothelium-specific hyaluronan receptor LYVE-I is expressed by stabilin-I+, F4/80+, CDIIb+ macrophages in malignant tumours and wound healing tissue in vivo and in bone marrow cultures in vitro: implications for the assessment of lymphangiogenesis. J Pathol 2006, 209:67-77.

25. Kerjaschki D, Huttary N, Raab I, Regele H, Bojarski-Nagy K, Bartel G, Krober SM, Greinix H, Rosenmaier A, Karlhofer F, Wick N, Mazal PR: Lymphatic endothelial progenitor cells contribute to de novo lymphangiogenesis in human renal transplants. Nat Med 2006, I 2:230-234

26. Ezaki T, Kuwahara K, Morikawa S, Shimizu K, Sakaguchi N, Matsushima K, Matsuno K: Production of two novel monoclonal antibodies that distinguish mouse lymphatic and blood vascular endothelial cells. Anat Embryol (Berl) 2006, 21 I:379-393.

27. Ji RC: Characteristics of lymphatic endothelial cells in physiological and pathological conditions. Histol Histopathol 2005, 20:I55- 175

28. Ji RC: Lymphatic endothelial cells, inflammatory lymphangiogenesis, and prospective players. Curr Med Chem 2007, | 4:2359-2368

29. Norgall S, Papoutsi M, Rössler J, Schweigerer L, Wilting J, Weich HA: Elevated expression of VEGFR-3 in lymphatic endothelial cells from lymphangiomas. BMC Cancer 2007 in press.

30. Wilting J, Papoutsi M, Christ B, Nicolaides KH, von Kaisenberg CS, Borges J, Stark GB, Alitalo K, Tomarev SI, Niemeyer C, Rossler J: The transcription factor Proxl is a marker for lymphatic endothelial cells in normal and diseased human tissues. Faseb | 2002, 16: 127|-|273

31. Scholzen T, Gerdes J: The Ki-67 protein: from the known and the unknown. J Cell Physiol 2000, 182:3II-322.

32. You LR, Takamoto N, Yu CT, Tanaka T, Kodama T, Demayo FJ, Tsai SY, Tsai MJ: Mouse lacking COUP-TFII as an animal model of Bochdalek-type congenital diaphragmatic hernia. Proc Natl Acad Sci U S A 2005/10/28 edition. 2005, 102:1635I-16356.

33. You LR, Lin FJ, Lee CT, DeMayo FJ, Tsai MJ, Tsai SY: Suppression of Notch signalling by the COUP-TFII transcription factor regulates vein identity. Nature 2005/05/06 edition. 2005, 435:98-104.

34. Pereira B, Bechara EJ, Mendonca JR, Curi R: Superoxide dismutase, catalase and glutathione peroxidase activities in the lymphoid organs and skeletal muscles of rats treated with dexamethasone. Cell Biochem Funct 1999/04/07 edition. 1999, I7:15-19.

35. Pereira RL, Ibrahim T, Lucchetti L, da Silva AJ, Goncalves de Moraes VL: Immunosuppressive and anti-inflammatory effects of methanolic extract and the polyacetylene isolated from Bidens pilosa L. Immunopharmacology 1999/08/07 edition. 1999, 43:3I-37.

36. Pereira FA, Qiu Y, Zhou G, Tsai MJ, Tsai SY: The orphan nuclear receptor COUP-TFII is required for angiogenesis and heart development. Genes Dev 1999/04/24 edition. 1999, I 3:1037-1049.

37. Okuda T, van Deursen J, Hiebert SW, Grosveld G, Downing JR: AMLI, the target of multiple chromosomal translocations in human leukemia, is essential for normal fetal liver hematopoiesis. Cell 1996, 84:321-330.

38. Obergfell A, Judd BA, del Pozo MA, Schwartz MA, Koretzky GA, Shattil S): The molecular adapter SLP-76 relays signals from platelet integrin alphallbbeta 3 to the actin cytoskeleton. J Biol Chem 2000/I2/13 edition. 200I, 276:5916-5923.

39. Mocsai A, Zhou M, Meng F, Tybulewicz VL, Lowell CA: Syk is required for integrin signaling in neutrophils. Immunity 2002/ 04/24 edition. 2002, 16:547-558.

40. Sebzda E, Hibbard C, Sweeney S, Abtahian F, Bezman N, Clemens G Maltzman JS, Cheng L, Liu F, Turner M, Tybulewicz V, Koretzky GA Kahn ML: Syk and Slp-76 mutant mice reveal a cell-autonomous hematopoietic cell contribution to vascular development. Dev Cell 2006/09/05 edition. 2006, I I:349-36I.

4I. Abtahian F, Guerriero A, Sebzda E, Lu MM, Zhou R, Mocsai A, Myers EE, Huang B, Jackson DG, Ferrari VA, Tybulewicz V, Lowell CA, Lepore J], Koretzky GA, Kahn ML: Regulation of blood and lymphatic vascular separation by signaling proteins SLP-76 and Syk. Science 2003, 299:247-25I.

42. Talbot NC, Worku M, Paape MJ, Grier P, Rexroad CE Jr., Pursel VG: Continuous cultures of macrophages derived from the 8-day epiblast of the pig. In Vitro Cell Dev Biol Anim 1996/I0/0I edition. 1996, 32:54I-549.

43. Kurz H, Christ B: Embryonic CNS macrophages and microglia do not stem from circulating, but from extravascular precursors. Glia 1998/01/22 edition. 1998, 22:98-102.

44. Malorny U, Michels E, Sorg C: A monoclonal antibody against an antigen present on mouse macrophages and absent from monocytes. Cell Tissue Res 1986, 243:421-428.

45. Flotte TJ, Springer TA, Thorbecke G]: Dendritic cell and macrophage staining by monoclonal antibodies in tissue sections and epidermal sheets. Am J Pathol 1983/04/0I edition. 1983, III:II2-I24.

46. Popichenko D, Paululat A: Cell fate decisions in the Drosophila dorsal vessel depend on the multiadapter protein inscuteable. Genesis 2004/I2/14 edition. 2004, 40:2 18-222

47. Duchek P, Rorth P: Guidance of cell migration by EGF receptor signaling during Drosophila oogenesis. Science 200I/0I/06 edition. 200|, 291:|3|-|33.

48. Duchek P, Somogyi K, Jekely G, Beccari S, Rorth P: Guidance of cell migration by the Drosophila PDGF/VEGF receptor. Cell 2001/10/12 edition. 200I, 107:17-26.

49. Heino TI, Karpanen T, Wahlstrom G, Pulkkinen M, Eriksson U, Alitalo K, Roos C: The Drosophila VEGF receptor homolog is expressed in hemocytes. Mech Dev 200I/I0/26 edition. 200I, 109:69-77.

50. Wilting J, Papoutsi M, Becker J: The lymphatic vascular system: secondary or primary? Lymphology 2004, 37:98-106.

5I. Meister M, Lagueux M: Drosophila blood cells. Cell Microbiol 2003/ 08/20 edition. 2003, 5:573-580.

52. Cho NK, Keyes L, Johnson E, Heller J, Ryner L, Karim F, Krasnow MA: Developmental control of blood cell migration by the Drosophila VEGF pathway. Cell 2002/04/17 edition. 2002, 108:865-876

53. Donoghue JF, Lederman FL, Susil BJ, Rogers PA: Lymphangiogenesis of normal endometrium and endometrial adenocarcinoma. Hum Reprod 2007/03/10 edition. 2007, 22:1705-17/3.

54. Geleff S, Schoppmann SF, Oberhuber G: Increase in podoplaninexpressing intestinal lymphatic vessels in inflammatory bowel disease. Virchows Arch 2003/03/2I edition. 2003, 442:23I-237.

55. Skobe M, Hawighorst T, Jackson DG, Prevo R, Janes L, Velasco P, Riccardi L, Alitalo K, Claffey K, Detmar M: Induction of tumor lymphangiogenesis by VEGF-C promotes breast cancer metastasis. Nat Med 2001/02/15 edition. 2001, 7:192-198.

56. Stacker SA Caesar C Baldwin ME Thornton GE, Williams RA, Prevo R, Jackson DG, Nishikawa S, Kubo H, Achen MG: VEGF-D promotes the metastatic spread of tumor cells via the lymphatics. Nat Med 2001/02/15 edition. 2001, 7:186-191.

57. Papoutsi M, Siemeister G, Weindel K, Tomarev SI, Kurz H, Schachtele C, Martiny-Baron G, Christ B, Marme D, Wilting J: Active interaction of human A375 melanoma cells with the lymphatics in vivo. Histochem Cell Biol 2000, I I 4:373-385.

58. Pepper MS, Skobe M: Lymphatic endothelium: morphological, molecular and functional properties. J Cell Biol 2003, 163:209-213

59. Rutkowski JM, Boardman KC, Swartz MA: Characterization of lymphangiogenesis in a model of adult skin regeneration. $\mathrm{Am}$ J Physiol Heart Circ Physiol 2006.

60. Schoppmann SF, Birner P, Stockl J, Kalt R, Ullrich R, Caucig C, Kriehuber E, Nagy K, Alitalo K, Kerjaschki D: Tumor-associated macrophages express lymphatic endothelial growth factors and are related to peritumoral lymphangiogenesis. Am J Pathol 2002/09/06 edition. 2002, 161:947-956.

6I. Skobe M, Hamberg LM, Hawighorst T, Schirner M, Wolf GL, Alitalo $\mathrm{K}$, Detmar M: Concurrent induction of lymphangiogenesis, angiogenesis, and macrophage recruitment by vascular endothelial growth factor-C in melanoma. Am J Pathol 2001/09/ II edition. 200I, I59:893-903.

62. Maruyama K, Asai J, li M, Thorne T, Losordo DW, D'Amore PA: Decreased macrophage number and activation lead to reduced lymphatic vessel formation and contribute to impaired diabetic wound healing. Am J Pathol 2007, 170:1178-1191.

63. Hamrah P, Chen L, Cursiefen C, Zhang Q, Joyce NC, Dana MR: Expression of vascular endothelial growth factor receptor-3 
(VEGFR-3) on monocytic bone marrow-derived cells in the conjunctiva. Experimental Eye Research 2004, 79:553-561.

64. Dictor M: Kaposi's sarcoma. Origin and significance of lymphaticovenous connections. Virchows Arch A Pathol Anat Histopathol 1986, 409:23-35.

65. Rutgers JL, Wieczorek R, Bonetti F, Kaplan KL, Posnett DN, Friedman-Kien AE, Knowles DM 2nd: The expression of endothelial cell surface antigens by AIDS-associated Kaposi's sarcoma. Evidence for a vascular endothelial cell origin. Am J Pathol 1986, I 22:493-499.

66. Uccini S, Sirianni MC, Vincenzi L, Topino S, Stoppacciaro A, Lesnoni La Parola I, Capuano M, Masini C, Cerimele D, Cella M, Lanzavecchia A, Allavena P, Mantovani A, Baroni CD, Ruco LP: Kaposi's sarcoma cells express the macrophage-associated antigen mannose receptor and develop in peripheral blood cultures of Kaposi's sarcoma patients. Am J Pathol 1997, I 50:929-938.

67. Banerji S, Ni J, Wang SX, Clasper S, Su J, Tammi R, Jones M, Jackson DG: LYVE-I, a new homologue of the CD44 glycoprotein, is a lymph-specific receptor for hyaluronan. IJ Cell Biol 1999, | 44:789-80|.

68. Prevo R, Banerji S, Ferguson DJ, Clasper S, Jackson DG: Mouse LYVE- $I$ is an endocytic receptor for hyaluronan in lymphatic endothelium. J Biol Chem 200I, 276:19420-19430.

Publish with Biomed Central and every scientist can read your work free of charge

"BioMed Central will be the most significant development for disseminating the results of biomedical research in our lifetime. "

Sir Paul Nurse, Cancer Research UK

Your research papers will be:

- available free of charge to the entire biomedical community

- peer reviewed and published immediately upon acceptance

- cited in PubMed and archived on PubMed Central

- yours - you keep the copyright 